\begin{tabular}{|c|c|c|c|}
\hline Case Renorts in & \multicolumn{2}{|c|}{ Case Rep Gastroenterol 2019;13:173-177 } & \multirow[b]{2}{*}{$\begin{array}{l}\text { Karger } \\
\text { Open access }\end{array}$} \\
\hline Gastroenterology & $\begin{array}{l}\text { DOI: 10.1159/000499443 } \\
\text { Published online: April 9, } 2019\end{array}$ & \begin{tabular}{|l|} 
( 2019 The Author(s) \\
Published by S. Karger AG, Basel \\
www.karger.com/crg
\end{tabular} & \\
\hline & $\begin{array}{l}\text { This article is licensed under } \\
\text { International License (CC BY-I } \\
\text { Usage and distribution for comr }\end{array}$ & $\begin{array}{l}\text { nons Attribution-NonCommercia } \\
\text { ger.com/Services/OpenAccessLice } \\
\text { uires written permission. }\end{array}$ & \\
\hline
\end{tabular}

\title{
Repeated Enterocutaneous Fistula in a Munchausen Syndrome Patient
}

\author{
Toshiaki Hagiwara Shinya Munakata Shun Ishiyama Goto Michitoshi \\ Rina Takahashi Kazumasa Kure Kumpei Honjo Yurika Makino \\ Kazuhiro Sakamoto \\ Department of Coloproctological Surgery, Faculty of Medicine, Juntendo University, \\ Tokyo, Japan
}

\section{Keywords}

Munchausen syndrome $\cdot$ Enterocutaneous fistula $\cdot$ Factitious disorder

\begin{abstract}
Munchausen syndrome is a rare type of mental disorder in which the patient fakes illness to gain attention and sympathy. Patients may lie about symptoms, make themselves appear sick, or make themselves purposely unwell. We describe a case of repeated enterocutaneous fistula in Munchausen syndrome. A 53-year-old Japanese male was admitted to our hospital for the treatment of a high-flow enterocutaneous fistula. Surgery was performed two times, but the fistula recurred each time. Chopsticks with blood on them were coincidentally detected in the trash in the patient's room. It was revealed that the enterocutaneous fistula was caused by selfmutilation. A psychiatrist was consulted, and the patient was diagnosed with Munchausen syndrome. The psychiatrist initiated treatment and the patient admitted the self-harm. His prolonged wound site was closed and he was able to be discharged. There has been no recurrence of the self-harm as of this writing, 3 years later. The treatment of Munchausen syndrome is difficult and early detection is important.




\section{Case Reports in Gastroenterology}

Case Rep Gastroenterol 2019;13:173-177

DOI: 10.1159/000499443

(c) 2019 The Author(s). Published by S. Karger AG, Basel www.karger.com/crg

Hagiwara et al.: Repeated Enterocutaneous Fistula in a Munchausen Syndrome Patient

\section{Background}

Munchausen syndrome is a rare type of mental disorder in which the patient fakes an illness to gain attention and sympathy. Individuals with Munchausen syndrome may lie about symptoms, make themselves appear sick, or make themselves purposely unwell [1, 2]. Patients with Munchausen syndrome can be very convincing, which can result in physicians providing unnecessary medication or even surgery. The health care providers treating such patients may quickly become frustrated by their demanding interpersonal styles, by the deception and manipulation, and by multiple uninformative diagnostic procedures. These difficulties can lead to poor outcomes. This type of mental disorder is most often seen in young adults and is considered a type of self-harm [1]. Oftentimes, patients with Munchausen syndrome have experienced childhood abuse.

Enterocutaneous fistulas (ECFs) are abnormal connections between the intestinal cavity and the skin, which occur as a postoperative complication in $0.8-2 \%$ of abdominal surgeries [3]. Here we report a rare case of ECF caused by self-harm with a screwdriver and chopsticks.

\section{Case Presentation}

A 53-year-old Japanese man was admitted to our hospital for the treatment of a high-flow ECF. His medical history was remarkable for a right-sided paralysis and type I diabetes. At physical examination, his weight was $104 \mathrm{~kg}$, height $1.84 \mathrm{~m}$, and body mass index $30.7 \mathrm{~kg} / \mathrm{m}^{2}$. He had undergone a right nephrectomy 10 years earlier with the diagnosis of renal cell carcinoma.

After his admission, our plastic surgeon treated the surgical wound, but the abdominal wound suppurated and showed no indication of recovery (Fig. 1). Upper gastrointestinal radiography confirmed that a rupture of the intestine had occurred, and a jejunal fistula was observed (Fig. 2). The patient reported experiencing gradually severe abdominal pain and wound pain, and he exhibited a continuous fever.

The repair surgery was performed immediately with open surgery because of the uncontrolled enteric fluid. Small bowel resection with the fistula was done under general anesthesia. We performed a functional end-to-end anastomosis using the Endo GIA ${ }^{\text {TM }}$ Reinforced stapler.

On postoperative day 16 , a surgical site infection was noted. Washing out the wound improved the infection, but wound dehiscence spread along the surgical wound. Because the wound pain was prominent, a second operation was performed, including the debridement and resuturing of the fascia under general anesthesia. Using the vacuum-compaction device proved effective for reducing the fistula. After we informed the patient of the discharge date, the ECF relapsed with high-flow intestinal fluid. At the same point in time, a member of our medical staff witnessed the patient's self-harm to the wound with a screwdriver and chopsticks. Blood adhered to the chopsticks, which were discarded in the trash box in the patient's room. A psychiatrist was then consulted, and the patient admitted the self-harm.

A third surgery with a second intestinal resection was performed. The surgical wound remained open and washing out the wound was done every day. On postoperative day 19, the prolonged wound site was closed and the patient was discharged (Fig. 3). There has been no recurrence of the self-harm as of this writing, 3 years after the third surgery. 


\section{Discussion}

The label "Munchausen's syndrome" was devised by Richard Asher to describe patients who consistently produce false stories and who fabricate evidence in order to gain attention and undergo needless medical investigations, treatments, and even surgery [4]. The self-inflicted illnesses and injuries of individuals with Munchausen syndrome can have very serious consequences. These individuals often undergo several unnecessary surgeries throughout their lifetime.

As for our patient, we performed surgery for the wound sequelae three times and a smallintestinal resection two times because we did not originally recognize his self-mutilation. Unfortunately, his self-harm caused a high-output ECF. The management of a high-output ECF is complex and challenging. It involves nutrition, medical, skin care, and psychological treatment. Patients with high-output ECFs have a high morbidity rate (16\%) and a high mortality rate (30\%) [5]. The reported healing rate is $69-93 \%$ even after definitive fistula surgery [5, 6]. Our patient's self-harm contributed to the low closure rate, and his condition was not always favorable.

There are few reports describing the management of factitious disorders (including Munchausen syndrome), and there have been no treatment studies. The first goal of treatment is the reduction or elimination of potentially harmful investigations and procedures. Confronting a patient suspected of self-harm should take place in a sympathetic and nonpunitive way. The involvement of a psychiatrist with the offer of continuing support can be helpful. After diagnosis and confrontation, many patients will show some improvement with a reduction in the factitious behavior, even though they might continue to deny their role in the creation of the symptoms and refuse continuing psychiatric care [7].

Treatment is likely to focus on changing the thinking and behavior of the individual (cognitive-behavioral therapy). Family therapy might also be helpful in teaching family members not to reward or reinforce the behavior of the person with the disorder, but often the person is estranged from his or her family. Group therapy may reduce feelings of isolation or that no one cares for them. There are no medicines to treat factitious disorders themselves. However, medicine might be used to treat related disorders such as depression, anxiety, or a personality disorder. The use of medicines must be carefully monitored in people with factitious disorders due to the risk that the drugs might never be picked up from the pharmacy or might be used in a harmful way.

We hesitated to point out that our patient self-harmed, cutting and scratching his wound. The psychiatrist helped him to accept and overcome the self-harm and discussed his anxiety regarding his future. The patient was eventually able to discontinue the self-injury.

In conclusion, we have reported a repeated ECF in a patient who was revealed to have Munchausen syndrome. The treatment of Munchausen syndrome is difficult, and early detection is important.

\section{Statement of Ethics}

The authors have no ethical conflicts to disclose. This study was performed in accordance with the ethical standards of the Committee on Human Experimentation of our institution. 


\section{Case Reports in Gastroenterology}

\begin{tabular}{l|l}
\hline DOI: $10.1159 / 000499443$ & (c) 2019 The Author(s). Published by S. Karger AG, Basel
\end{tabular} www.karger.com/crg

Hagiwara et al.: Repeated Enterocutaneous Fistula in a Munchausen Syndrome Patient

\section{Disclosure Statement}

The authors have no conflicts of interest to declare.

\section{Author Contributions}

Data acquisition: T.H., S.M., S.I., G.M., Y.T., R.T., K.K., K.H., and Y.M. Drafting of the manuscript: S.M. and T.H. Critical revision of the manuscript: K.S.

\section{References}

1 Turner J, Reid S. Munchausen's syndrome. Lancet. 2002 Jan;359(9303):346-9.

2 Huffman JC, Stern TA. The diagnosis and treatment of Munchausen's syndrome. Gen Hosp Psychiatry. 2003 Sep-Oct;25(5):358-63.

3 Wainstein DE, Fernandez E, Gonzalez D, Chara O, Berkowski D. Treatment of high-output enterocutaneous fistulas with a vacuum-compaction device. A ten-year experience. World J Surg. 2008 Mar;32(3):430-5.

4 Asher R. Munchausen's syndrome. Lancet. 1951 Feb;1(6650):339-41.

5 Draus JM Jr, Huss SA, Harty NJ, Cheadle WG, Larson GM. Enterocutaneous fistula: are treatments improving? Surgery. 2006 Oct;140(4):570-6.

6 Hollington P, Mawdsley J, Lim W, Gabe SM, Forbes A, Windsor AJ. An 11-year experience of enterocutaneous fistula. Br J Surg. 2004 Dec;91(12):1646-51.

7 Reich P, Gottfried LA. Factitious disorders in a teaching hospital. Ann Intern Med. 1983 Aug;99(2):240-7.

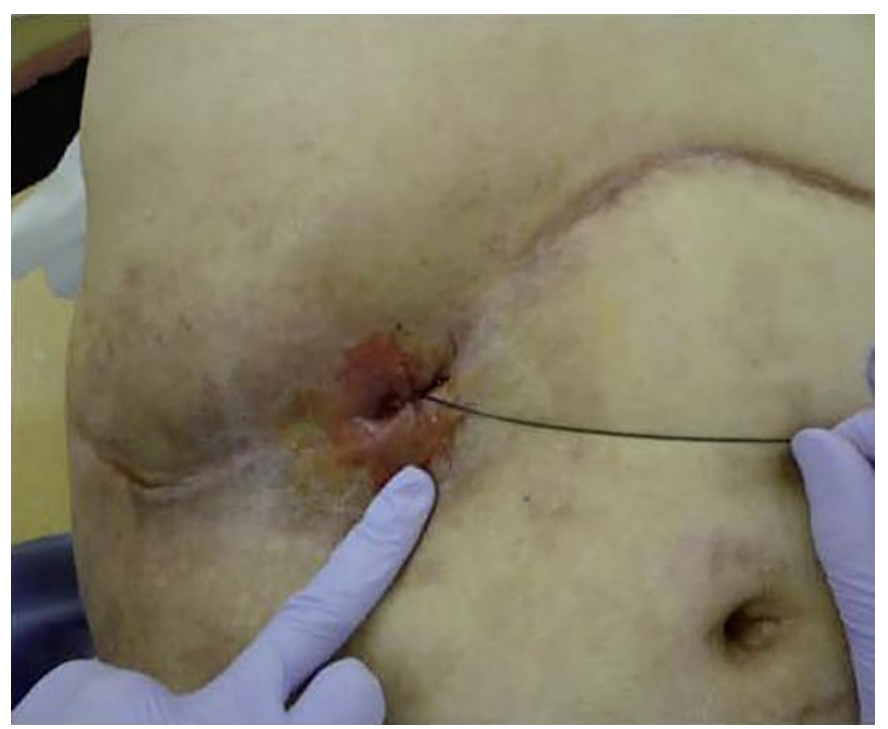

Fig. 1. The enterocutaneous fistula and wound appearance on admission. 


\section{Case Reports in Gastroenterology}

\begin{tabular}{l|l}
\hline Case Rep Gastroenterol 2019;13:173-177 \\
\hline DOI: 10.1159/000499443 & $\begin{array}{l}\text { @ 2019 The Author(s). Published by S. Karger AG, Basel } \\
\text { www.karger.com/crg }\end{array}$ \\
\hline
\end{tabular}

Hagiwara et al.: Repeated Enterocutaneous Fistula in a Munchausen Syndrome Patient

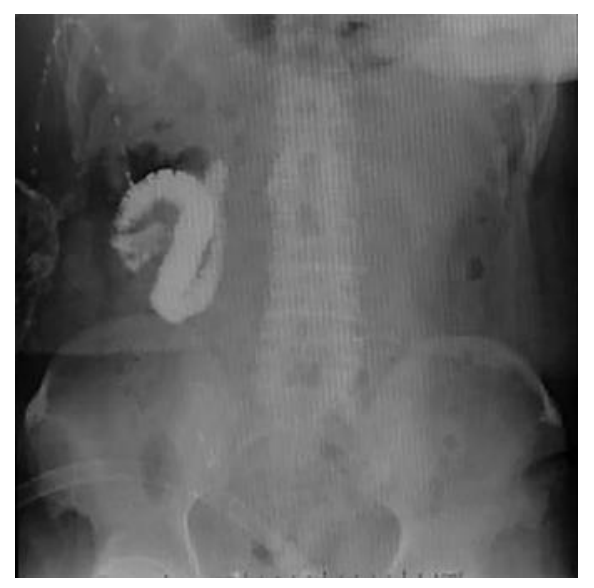

Fig. 2. Upper gastrointestinal radiography image showing jejunal perforation.

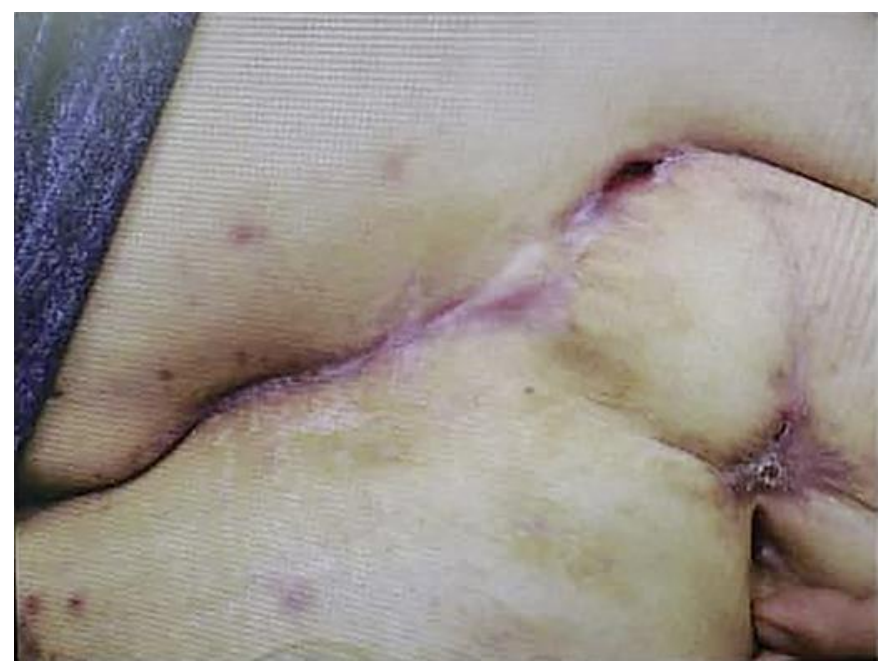

Fig. 3. The wound after the third operation for the enterocutaneous fistula. 